\title{
A freight urban distribution center design with micro-simulation support for city logistics
}

\author{
D. Gattuso, G. C. Cassone, C. Lanciano, V. Placido \& M. Praticò \\ DIIES - Dipartimento di Ingegneria dell'Informazione, \\ delle Infrastrutture e dell'Energia Sostenibile, \\ Università Mediterranea di Reggio Calabria, Italy
}

\begin{abstract}
The performance of a freight interchange warehouse can be improved and/or enhanced through the analysis, study and optimization of active processes for the treatment/handling of goods. This paper proposes a discrete event microsimulation model as a tool useful to design a freight interchange warehouse and, particularly, to manage the exchange of freights between heavy lorries, coming from extra-urban regions, and small electric vans used for urban distribution. In particular, the paper focuses on dimensioning the warehouse structure and handling means in order to optimize the operational activities in relation to inbound freight flows (vehicles from extra-regional areas) and outbound freight flows (urban distribution service). The micro-simulation model allowed ex-ante and ex-post evaluations proving to be a useful decision support tool in planning. Keywords: city logistics, urban distribution center, micro-simulation, performance evaluation.
\end{abstract}

\section{Introduction}

The attention on the freight component has been growing in the management of urban mobility. The city is not only a delimited area in which people move, but also a space expressing relevant economic factors. These factors are fundamental for the community and produce freight flows. That is why many European cities have started innovative policies to optimize the freight distribution in urban areas.

An urban distribution centre (UDC) is a useful city logistics policy tool that can produce interesting impacts on the dynamics of urban freight distribution. Its success depends on many factors: an appropriate location; a well-balanced 
presence of spaces and equipment; an efficient and effective organization of internal services; a connection with the surrounding area and with the related transport services; a management structure that meets different and complementary requirements; a capacity to support itself.

This paper analyses the problems related to the functional organization of a UDC by using a micro-simulation approach in order to define the layout, to verify the efficiency and to optimize the relation between inbound flows (heavy vehicles) and outbound flows (light and ecological vehicles) with a view to reducing the negative impacts on the urban context.

The paper also presents a specific applicative case concerning the design of the main attributes of a UDC in a medium-sized city in the South of Italy.

\section{UDC design: some references in a recent literature review}

In recent years, research has been focusing on the problems related to the location of a UDC, to its layout and dimensioning, to the management and optimization of its internal activities and to the analysis of the node in relation to the distribution context.

With reference to its location, a UDC can be situated either in an urban or in a suburban context. In the former case, the UDC is near demand points and is small; in the latter case, the UDC covers a high number of demand points and is large. In literature, many studies focus on problems related to the definition of the optimal location for a UDC $[1,2]$.

The definition of the layout, location and dimension of UDC functional elements is very important in order to make the terminal efficient. The layout of a UDC is closely related to the supply chain, to the quantity of goods that must be processed and to the choices made during its design in relation to goods handling. In literature, guidelines concerning the functional structure of UDCs, the number of inbound/outbound gates [3], the dimensioning and organization of covered and uncovered spaces and of the total surface of UDC $[4,5]$ are reported.

Many researchers deal with the optimization of UDC functional activities. They often face problems related to scheduling and assignment of the inbound/outbound vehicles [6-9]; to handling activities and their organization [10-14].

In addition, many studies approach the node analysis by taking into account the characteristics of the transport network [1, 15-19]. In these cases, the performance evaluation and the optimization of the UDC are carried out considering the relations between the node and the served territorial context.

\section{Functional and dimensional characteristic of UDC}

A UDC can be defined as " $a$ logistic platform for the centralized management of takings and deliveries, which is aimed at goods distribution in an urban area through the aggregation of freight flows and the optimization of routes" [1]. In other words, a UDC is a logistic platform of cross-docking where goods directed 
to an urban area are received and distributed and groupage/degroupage activities are carried out.

The physical and organizational structure of a UDC is closely related to the reference supply chain, to the dimension of handling load units (little boxes, pallets, bulky goods), to the involved stakeholders.

Generally a typical structure of a UDC can be schematized in six functional areas (Figure 1): the input doors, reserved to heavy vehicles coming from hinterland with goods directed to the city; the receipt area where the activities of unload and the qualitative and quantitative checks are operated; the sorting area where the inbound loads are broken down and the boxes are assigned to specific areas of warehouse; the storage area conveniently organized in order to keep the sorted goods; the consignment area where the outbound load are composed; the output doors across the freights are loaded on vans or light lorries for urban distribution.

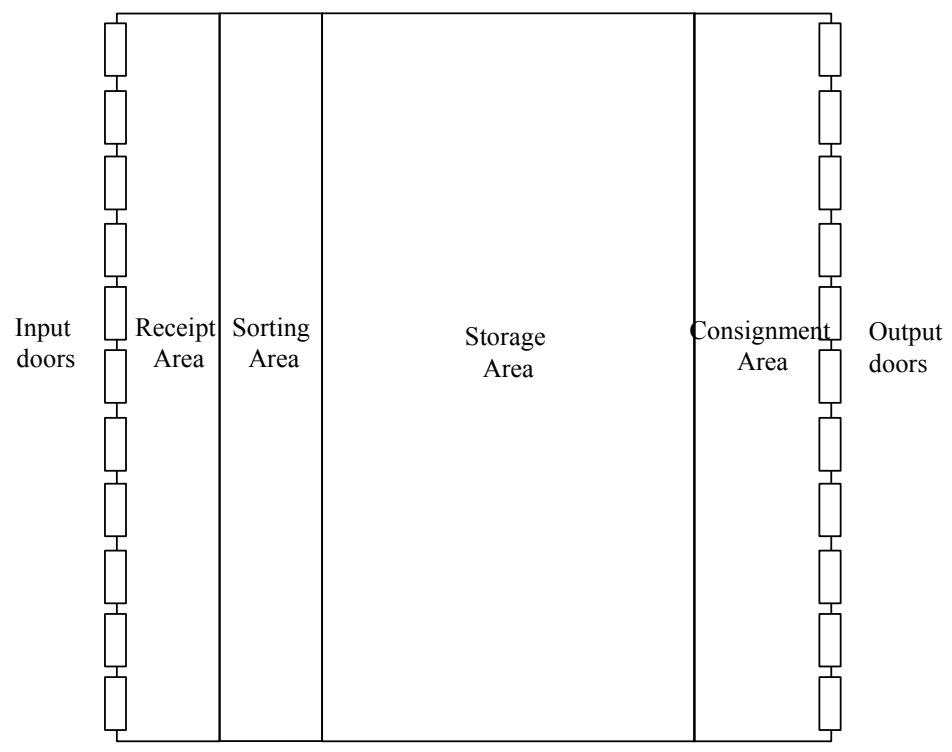

Figure 1: Typical layout of a UDC.

The dimensioning of different areas is related to the implementation of the specific activities and they are influenced by many factors, e.g. the size of the good flows, the type of activities, the links to external routes and transport system, the building layout, the dimensions of handling means, the organization of storage area, the characteristics of commercial vehicles which must be served.

\section{Micro-simulation model}

The analysis of a logistic warehouse functionality, and in particular of a UDC, can be realized by using simulation tools. 
The proposed model is a useful decision support tool for operators of existing UDC, since it enables them to make operational evaluations (space organization, resources utilization, etc.) that can direct the planning of tactical and strategic actions. Furthermore, in the case of the UDC still to be built, the proposed simulation model allows to test scenarios and to make informed choices about the provision of space and resources and about the management approach to be taken in planning phase.

In this study, the operational activities of a UDC have been simulated by using a stochastic, dynamic, discrete-event simulation approach. Discrete-event simulation is based on the chronological representation of the states through which the system evolves during a given time interval. The system is divided into independent elements (entities), which have peculiar characteristics (attributes) and interact through specific relations in order to carry out activities (subjected to constraints) that generate events able to change the state of the system itself. Then, an event driven simulation has been used, where the "simulation clock" was initialized to zero and advanced to the time of the occurrence of the first of the following events, which usually corresponds to the end or the beginning of an activity. The micro-simulation model has been specified, calibrated and implemented by using WITNESS software. The following paragraphs illustrate the phases of the model building.

\subsection{Model specification}

The model specification is related to the definition both of conceptual model and of system variables.

The conceptual model can be defined as the whole of the processes taking place in the analysis system and allows understanding the operational logic of the system itself. Therefore, the definition of the conceptual model aims at detecting and modelling the significant components of the system to be simulated as well as the specific relations existing between them. This phase is very important since it enables to define the flows and the routes of the entities that cross the analyzed system. The conceptual model for the simulation of an UDC was constructed by consecutive steps, gradually increasing the level of detail of its representation (Fig. 2).

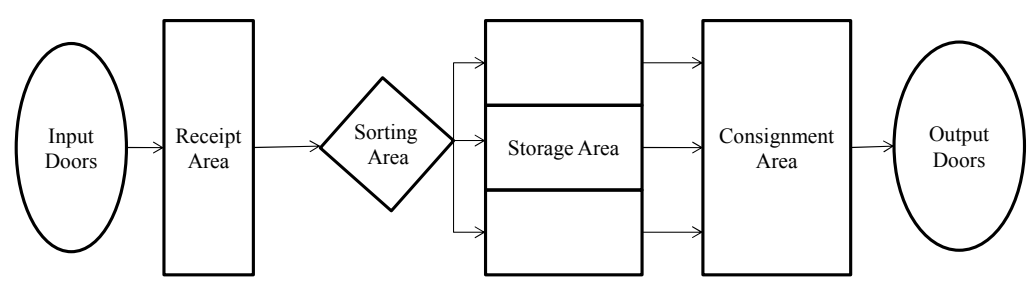

Figure 2: Conceptual model. 
The reference variables considered in the micro-simulation model specification are supply variables. The following are the supply variables considered:

- the unload time of heavy vehicles (Trucks) arriving $\left(T_{\text {unload }}\right)$;

- the degroupage and sorting time of inbound pallet ( $\left.T_{\text {degroupage }}\right)$;

- the handling $\left(T_{H}\right)$;

- the load time on light vehicles outgoing for urban distribution $\left(T_{\text {load }}\right)$.

\subsection{Model calibration}

The simulation model calibration implies the knowledge of the probability distributions of the reference variables and consists in the evaluating of the corresponding characteristic parameters. Parameters are assigned with the purpose of obtaining the state variables, which are as similar as possible to real values.

The model calibration has been realized with reference to previous studies on logistics UDC operative in regional/local context $[20,21]$. It was based on the statistical analysis of data collected through direct surveys at existing freight interchange sites.

Table 1 shows the calibration results.

Table 1: Calibration results.

\begin{tabular}{lrrll}
\hline Variables & $\mu($ min $)$ & $\sigma($ min $)$ & Distribution & Parameters \\
\hline$T_{\text {unload }}($ min $)$ & 15 & 8.13 & Gauss & $\mu=15 ; \sigma=8.13$ \\
\hline$T_{S}($ min $)$ & 4.19 & 3.83 & Exponential & $\theta=0.24$ \\
\hline$T_{H}($ min $)$ & 3.67 & 0.7 & Gauss & $\mu=3.67 ; \sigma=0.7$ \\
\hline$T_{\text {load }}($ min $)$ & 29 & 9 & Gamma & $k=0.363 ; \lambda=10.66$ \\
\hline$\mu=$ average; $\sigma=$ standard deviation. & \\
$k=$ shape parameter; $\lambda=$ scale parameter. &
\end{tabular}

\subsection{Model implementation}

The discrete-event micro-simulation model was implemented by means of WITNESS software; discrete elements were associated with the operational areas of the UDC and to the activities/operations performed to offer services to inbound lorries, to process inbound goods in internal warehouse and to deliver freights exiting to light electric vehicles.

In particular, inbound trucks, pallets unloaded, elementary boxes composing the load units and electric vehicle for local distribution were represented as parts. The operational areas of the node, i.e. the receipt area, the warehouse and the shipping area were represented as buffers. The operational activities into the UDC were instead represented as machines. 


\section{Application}

A specific application has been implemented, concerning the layout definition, the dimensioning and the efficiency analysis of an UDC for the city logistics in urban area of Reggio Calabria (Italy).

The layout definition and the dimensioning of spaces and of handling means have been treated with simulation approach considering the potential freight flows that the UDC will have to manage. It is assumed that, in an average weekday, $500 \mathrm{mc}$ of goods in standard boxes (dimensions: 60x80x60 cm) are directed to urban center.

In addition, it is supposed that:

- a load factor of inbound trucks is the same as $85 \%$;

- unitized inbound goods, in other words inbound load units are Euro Pallet (dimensions: 120x80x170 cm);

- electrical vehicles with the same capacity as $3 \mathrm{mc}$ (10 boxes) for urban distribution.

Figure 3 shows the UDC layout and Table 2 shows the results of dimensioning of the UDC areas.

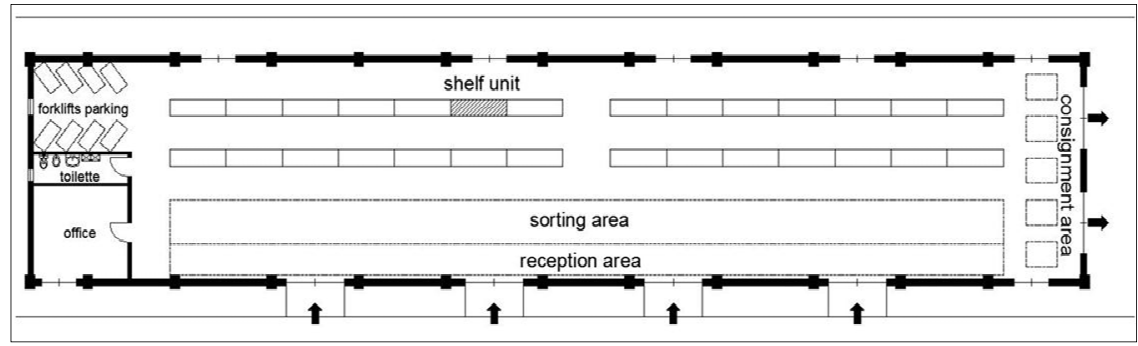

Figure 3: Layout of UDC.

Table 2: Dimensions of the UDC areas.

\begin{tabular}{lcccc}
\hline Area & Length $(\mathrm{m})$ & Width $(\mathrm{m})$ & Surface $(\mathrm{mq})$ & Capacity \\
\hline Receipt & 43 & 1.5 & 65.0 & \\
Sorting & 43 & 2.1 & 90.0 & \\
Storage & 43 & 4.9 & 210.7 & 560 boxes \\
Consignment & 4 & 10.4 & 41.6 & 5 complete loads \\
Forklifts & 5 & 4.3 & 22.0 & 8 forklifts \\
Parking & & & & \\
Offices & 4 & 5.9 & 29.0 & \\
\hline
\end{tabular}

There are 6 doors for entrance/exit: 4 are reserved to heavy vehicles (trucks) coming from hinterland and two are reserved to electrical vehicle for urban distribution. 
The storage area is equipped with modular traditional shelf; each shelf unit (dimensions: 290x80 cm) is designed to contain the boxes for a specific urban tour.

The simulation gave necessary information on number and type of means that must be used for loading, unloading and handling. Figure 4 shows the adopted handling means and Table 3 shows their technical characteristics.

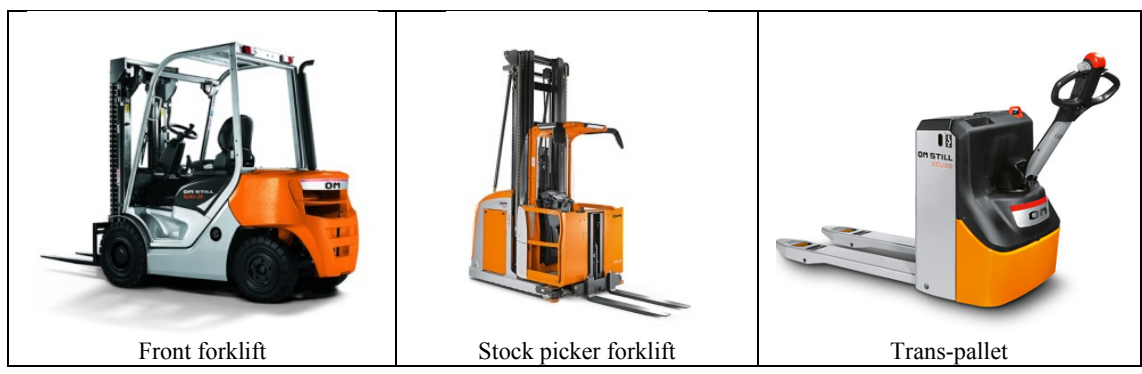

Figure 4: Handling means.

Table 3: Characteristics of handling means.

\begin{tabular}{|c|c|c|c|}
\hline Activity & Means & Number & Characteristics \\
\hline Unloading & Front forklift & 2 & $\begin{array}{l}\text { Length:4.60 m; Width: } 1.7 \mathrm{~m} \\
\text { Max. payload: } 5,000 \mathrm{~kg} ; \\
\text { Max. height: } 6 \mathrm{~m} \\
\text { Speed: } 19 \mathrm{~km} / \mathrm{h}\end{array}$ \\
\hline Handling & $\begin{array}{l}\text { Stock picker } \\
\text { forklift }\end{array}$ & 4 & $\begin{array}{l}\text { Length: } 2.45 \mathrm{~m} \text {; Width: } 0.98 \mathrm{~m} \\
\text { Max. payload: } 1,200 \mathrm{~kg} \text {; } \\
\text { Max. height: } 10 \mathrm{~m} \\
\text { Speed: } 10 \mathrm{~km} / \mathrm{h}\end{array}$ \\
\hline Loading & Trans-pallet & 2 & $\begin{array}{l}\text { Length: } 1.60 \mathrm{~m} \text {; Width: } 0.72 \mathrm{~m} \\
\text { Max. payload: } 1,400 \mathrm{~kg} \text {; } \\
\text { Max. height: } 0.123 \mathrm{~m} \\
\text { Speed: } 5 \mathrm{~km} / \mathrm{h}\end{array}$ \\
\hline
\end{tabular}

In order to separate the inbound and outbound flows, to manage efficiently handling activities and to limit the use of means and human resources, the following organizational set-up of operative times is considered:

- freight receiving in the afternoon;

- urban distribution in the morning (beginning at 6 o'clock).

UDC efficiency and the evaluation of times to cross the node have been analyzed by using the proposed micro-simulation model.

The output parameters obtained by simulation are: average unloading time; average sorting time; average handling time from sorting area to storage area; average storage time; average handling time to setup outbound load; average 
occupation time of consignment buffers; average loading time; average time to cross UDC; average time of a tour for urban distribution; number of urban tours.

Table 4 shows the simulation results. It shows that average times to receiving and handling of inbound freight are equal to 35 minutes (the unloading and sorting activities take place in the same time). The consignment area presents a high congestion in waiting buffers that are busy for 84 minutes for the urban distribution and the effective availability of electrical vehicles.

Moreover, the simulation results show that the analyzed UDC efficiency is good: after a working day, the number of boxes in storage area is minimum (30 boxes) and 47/50 loads directed to the city are handled.

Table 4: Simulation results.

\begin{tabular}{|c|c|c|c|}
\hline & & $\begin{array}{l}\text { Value } \\
\text { (min) }\end{array}$ & $\begin{array}{r}\text { Standard } \\
\text { deviation } \\
\text { (min) }\end{array}$ \\
\hline Average unloading time & Truck & 14.82 & 1.14 \\
\hline Average sorting time & Pallet & 4.04 & 0.57 \\
\hline $\begin{array}{l}\text { Average handling time from sorting area to } \\
\text { storage area }\end{array}$ & Box & 16.08 & 11.09 \\
\hline Average storage time & Box & $1,054.69$ & 67.63 \\
\hline $\begin{array}{l}\text { Average handling time to setup outbound } \\
\text { load }\end{array}$ & Box & 22.02 & 1.02 \\
\hline $\begin{array}{l}\text { Average occupation time of consignment } \\
\text { buffers }\end{array}$ & $\begin{array}{l}\text { Outbound } \\
\text { load }\end{array}$ & 83.33 & 57.15 \\
\hline Average loading time & $\begin{array}{l}\text { Outbound } \\
\text { load }\end{array}$ & 25.45 & 0.86 \\
\hline Average time of a tour & ETV & 24.33 & 10.50 \\
\hline Number of urban tours & ETV & 47 & \\
\hline
\end{tabular}

\section{Conclusion}

The simulation of the logistic activities of a UDC is a fundamental tool to optimize the activities and to evaluate its performance and impact on the city.

The paper proposes a methodology to analyse the problems related to the functional organization of a UDC through a micro-simulation approach. The aims of the research has been the layout definition, the dimensioning of internal spaces of the UDC and the evaluation of UDC efficiency.

\section{Acknowledgements}

Cosimo Lanciano, Vincenzo Placido, and Massimo Praticò collaborated to the application as students of the Master of Transportation Engineering, supplied in 2014-2015 at Dipartimento di Ingegneria dell'Informazione, delle Infrastrutture e dell'Energia Sostenibile of Università Mediterranea di Reggio Calabria. 


\section{References}

[1] Da Rios G., Gattuso D. La mobilità delle merci nell'area metropolitana milanese. Franco Angeli, Milano, 2003.

[2] Dobrusky F.G. Optimal Location of Cross-Docking Centers for a Distribution Network in Argentina. Massachusetts Institute of Technology Libraries, 2003.

[3] Bartholdi J. J., Gue K. R. Reducing Labor Costs in an LTL Cross-docking Terminal. Operations Research, N. 48, 2000.

[4] d'Elia S., Festa D.C., Mazzulla M. La distribuzione delle merci nell'area urbana di Cosenza: proposta di una struttura logistica innovativa, Centro Editoriale e Librario, Università della Calabria-Rende, 2004.

[5] Panuccio P., Amodeo L., D'Agostino P., Lamari D. \& T. Scattarreggia. Urban regeneration and smart city according EU strategies: urban distribution center in city logistics. In WIT Transactions on the Built Environment, volume 146, 2015. ISSN: 1746-4498, Digital ISSN: 17433509.

[6] Bozer Y., Carlo H. Optimizing inbound and outbound door assignments in less-than-truckload crossdock. IIE Transactions, N. 40, pp. 1007-1018, 2008.

[7] Tsui L.Y., Chang C.H. An optimal solution to dock door assignment problem. Computers \& Industrial Engineering, N. 23, pp. 283-286, 1992.

[8] Gue K.R. The effect of trailer scheduling on the layout of freight terminals. Transportation Science, N. 33, pp. 419-428, 1999.

[9] Boysen N., Fliedner M., Scholl A. Scheduling inbound and outbound trucks at cross docking terminals. OR Spectrum N. 32 pp. 135-161, 2010.

[10] Li Y., Lim A., Rodrigues B. Crossdocking-JIT scheduling with time windows. Journal of the Operational Research Society, N. 55, pp. 1342 1351, 2004.

[11] Vis I.F.A., Roodbergen K.J. Positioning of goods in a cross-docking environment. Computers \& Industrial Engineering, N 54, pp. 677-689, 2008.

[12] Alvarez-Perez G.A., Gonzalez-Velarde J.L., Fowler J.W. Crossdocking just in time scheduling: an alternative solution approach. Journal of the Operational Research Society, N. 60, pp. 554-64, 2009.

[13] Rong Zhu Y., Hahn P., Liu Y., Guignard-Spielberg M. New Approach for the Cross-Dock Door Assignment Problem. XLI SBPO 2009 - Pesquisa Operacional na Gestão do Conhecimento, 2009.

[14] Liu Y., Takakuwa S. Simulation-based personnel planning for materials handling at a cross-docking center under retail distribution environment. Proceedings of the 2009 Winter Simulation Conference, 2009.

[15] Russo, F. and Comi, A. City Characteristics and Urban Goods Movements: A Way to Environmental Transportation System in a Sustainable City. In: Procedia - Social and Behavioral Sciences 39, DOI: 10.1016/ j.sbspro.2012.03.091, Elsevier Ltd, pp. 61-73, 2012. 
[16] Gattuso D., Concettino S. Pianificazione della mobilità urbana tenendo conto dei servizi di logistica. Logistica Management, N. 157, pp. 89-100, 2005.

[17] Gattuso D., Concettino S. Servizi di logistica nella pianificazione della mobilità urbana. Uno stato dell'arte. Logistica Management, N. 156, pp. 89-94, 2005.

[18] Amodeo L., Lamari D., Musolino G., Placido V., Polimeni A., Praticò M. \& A. Vitetta. An ex-ante evaluation of last-mile freight distribution services for city logistics In WIT Transactions on the Built Environment, volume 146, 2015. ISSN: 1746-4498, Digital ISSN: 1743-3509.

[19] Gattuso D., Cassone G.C. Micro-simulation model supporting the management of an interregional logistic platform. Procedia - Social and Behavioral Sciences, Elsevier; $\mathrm{n}^{\circ} 54$ (2012) pp. 557-566, 2012. ISSN: 1877-0428.

[20] Gattuso D., Cassone G.C., Pellicanò D.S. A micro-simulation model for performance evaluation of a logistic platform. Transportation Research Procedia. Volume 3, 2014, pp. 574-583. 2014. ISBN: 978-84-617-1148-2.

[21] Russo F., Rindone C., D’Agostino P., Lanciano C. \& Scattarreggia T., Long distance freight transport to the provisioning of a city logistics. In WIT Transactions on the Built Environment, volume 146, 2015. ISSN: 1746-4498, Digital ISSN: 1743-3509. 